\title{
Prevalence of oral precancerous lesions and conditions among tobacco consumers in rural population around Belgaum. A community based cross sectional study.
}

\author{
${ }^{1}$ Dr Ashwini Narasannavar, ${ }^{2}$ Dr A S Wantamutte. \\ ${ }^{1}$ Lecturer, Department of Public Health, \\ ${ }^{2}$ Head Department of Community Medicine, USM KLE International Medical program.
}

\begin{abstract}
:
Background: Oral cancer is the 6th most common cancer in the world.2/3rd cases are contributed by the developing countries. India alone accounts for 1/3rd of the world's oral cancer and has a high rate of premalignant lesions. Most common predisposing factors are smoking, smokeless tobacco, betel nut in quid form (pan), alcohol, spicy food, sharp broken tooth. These lesions and conditions are considered suitable for screening as they have potential to change to cancer. Most of the screening services are available at hospitals; there is scarcity of screening services at the community level. Objective: to know the prevalence of oral precancerous lesions and conditions among tobacco consumers. Materials and Method: Study design: community based cross sectional study. Area: rural field practice area of JNMC. Study period: 5 months (July to Nov 2012) Sample size: 840 participants recruited by systematic random sampling method. Data collection: examined by visual examination. Data regarding age, sex, educational status, income, habits related to use of alcohol/tobacco were collected using pretested questionnaire. Results: $46 \%$ of the participants belonged to age of 20-30 years. Nearly $32 \%$ were labours who worked in the industries, small factories. Among these 840participants 232 were tobacco consumers. $87 \%$ were smokeless tobacco users and among them $37 \%$ had different oral lesions. Prevalence of precancerous lesion and condition was 51.21\%. Significant association was seen with type of tobacco used. Conclusion: The habit of tobacco chewing and smoking showed a statistically significant association to with oral lesions which were common in younger age group. Close follow up and systematic evaluation is required. There is an urgent need for awareness programs involving the community health workers, dentists and allied medical professionals.
\end{abstract}

Key words: precancerous lesion, tobacco, prevalence, rural area

\section{Introduction}

Oral diseases are major public health problem. Among them oral cancer is at the top of the list. Oral cancer is the $6^{\text {th }}$ most common cancer in the world which accounts for 350,000 new cases and 128,000 deaths annually. Two-third cases are contributed by the developing countries among the overall cases in the world ${ }^{1-2}$. It has been estimated that around $43 \%$ of cancer deaths are due to tobacco use, alcohol consumption, unhealthy intake of food, inactive lifestyles and infection ${ }^{1 .}$ India alone accounts for one third of the world's oral cancer and has a high rate of pre-malignant lesions. ${ }^{3}$ There are many factors causing precancerous lesions. Most common predisposing factors associated with oral lesions are: smoking, snuff, gutkha, betel nut in quid form (pan), alcohol, spicy food, malnutrition, improper oral hygiene, malocclusion, sharp broken tooth, ill fitting dentures etc. The most common oral precancerous lesions are: oral leukoplakia, erythroplakia, nicotina palati and oral sub mucous fibrosis. Others include candidiasis, recurrent herpes labialis, hairy tongue, lichen planus etc. Leukoplakia is seen as white patch in oral cavity commonly on buccal mucosa, gingival and tongue. ${ }^{4}$ Leukoplakia prevalence in India varies from $0.2 \%-5.2 \% .^{5}$ the overall prevalence of precancerous lesion among patients attending hospital in certain places of India range between $2.5 \%$ to $8.4 \%{ }^{6,7}$. Oral premalignant lesions have shown a rate of progression to cancer up to $17 \%$ within a mean period of 7 years after diagnosis. In developed countries, the highest transformation rate is seen in lesions with clinically irregular or heterogeneous erythroplakia and dysplastic changes. In India a cohort study conducted in Ernakulum district of Kerala showed $79 \%$ of cancers arose from preexisting precancerous lesions and conditions ${ }^{8-10}$. Screening of apparently healthy individuals discloses cancer in early and precancerous stages and treatment will be most effective ${ }^{9}$. Oral cavity is easily accessible for screening and there are no embarrassing procedures involved in the oral cancer screening such as breast and cervix cancer screening ${ }^{9}$. Precancerous lesions and conditions are seen in healthy individual and hence can be identified by screening. Most of the screening services are available at hospitals; there is scarcity of screening services at the community level. Hence the present study is proposed to screen the oral cavity to identify the precancerous lesions among tobacco consumer in rural population around Belgaum. 
Objective: to know the prevalence of oral precancerous lesions and conditions among tobacco consumers.

\section{Materials and methodology:}

The present study is a community based cross sectional study conducted in a rural field practice area of Jawaharlal Nehru Medical College, Belgaum over a period of 5 months from July to November 2012. Ethical clearance was obtained from institutional ethics committee. All the individuals, of both sexes between 20-60 years of age, residing in study area and who gave written consent were included. Sample size was calculated by taking the least prevalence of oral precancerous lesion that is smokers' palate $\left(n=4 \mathrm{pq} / \mathrm{d}^{2}\right)$ and hence 840 was the sample size and were recruited by using systematic random sampling method. The participants were explained with the details of the study. The data regarding age, sex, occupation, educational status, income, (socio economic status was calculated by Modified B G Prasad classification) type of family, type of diet, habits related to use of alcohol/tobacco, type of tobacco used were collected by interview method using predesigned and pretested questionnaire. Visual examination of oral cavity was done using mouth mirror and probe after screening for tobacco consumption.

\section{Statistical Analysis:}

The data was analyzed using SPSS.20 software. The data is presented in percentages, rates and ratios. Chi square test was used to find the association between attributes.

\section{Results}

Out of all the participants, $46 \%$ of the participants belonged to age of $20-30$ years. $32 \%$ of them were labourers who worked in the industries, small factories, followed by $9.4 \%$ drivers and $7 \%$ businessman. (Table. no .1)

Graph. No.1: Age wise distribution of participants.

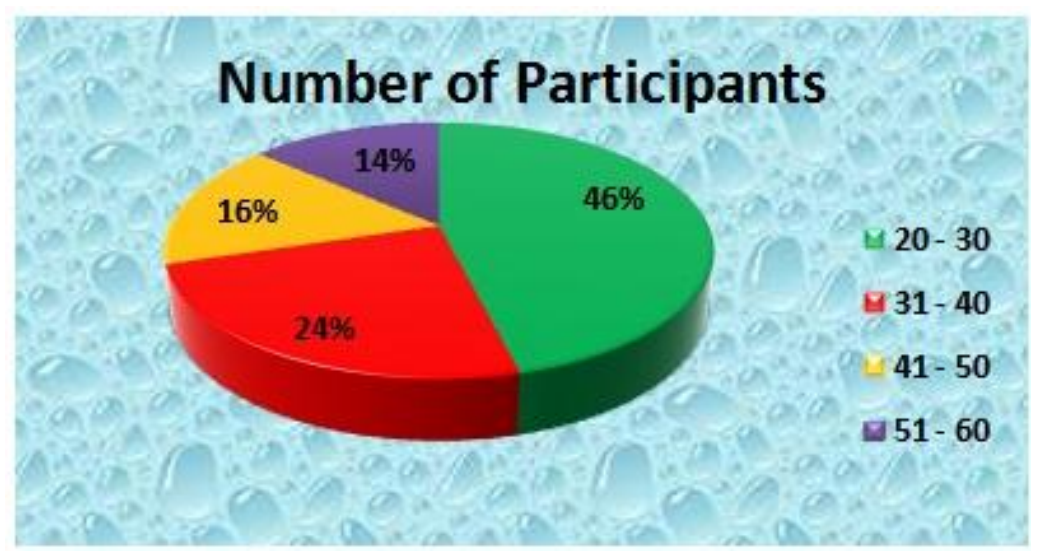

Among all participants 54\% were from joint family, 36\% from nuclear family and $10 \%$ from extended family. Among these 840 participants 232 were tobacco consumers. Among these tobacco consumers $89 \%$ had smokeless form of tobacco, $6 \%$ had smoking type and only $5 \%$ had combination of both the types. (Table No. 2)

Table No. 1: Distribution of participants according to occupation.

\begin{tabular}{|l|l|l|}
\hline Occupation & Number of Participants & Percentage \\
\hline Farmer & 29 & 3.4 \\
\hline Businessman & 57 & 6.7 \\
\hline Professional & 7 & 0.8 \\
\hline Labour & 267 & 31.5 \\
\hline Driver & 80 & 9.4 \\
\hline Others & 400 & 47.2 \\
\hline Total & 840 & 100.0 \\
\hline
\end{tabular}

Table No: 2: Number of participants according to type of tobacco habits.

\begin{tabular}{|l|l|l|}
\hline Tobacco Habits & Number of Participants & Percentage \\
\hline Smokeless & 206 & 88.79 \\
\hline Smoking & 14 & 6.04 \\
\hline Both & 12 & 5.17 \\
\hline Total & 232 & 100 \\
\hline
\end{tabular}


Smokeless forms were of different types like gutkha, betelnut, plain tobacco, pan with tobacco, tobacco with lime and other forms. (Table. No 3). 217 participants had the habit of tobacco chewing and out of them lesions were seen in $82(37.78 \%)$. The maximum percentage of participants having lesion had the habit of chewing plane tobacco $(50 \%)$, followed by tobacco and lime $(45.45 \%)$, pan and tobacco $(38.46 \%)$, guthka $(34.74 \%)$ and not a single participant having a lesion with the habit of chewing betel nut alone. There is significant association between type of chewing tobacco and oral lesion. (P Value $=0.000$ ).

Table. No 3. Prevalence of lesion according to smokeless tobacco.

\begin{tabular}{|l|l|l|l|l|l|l|l|}
\hline \multicolumn{2}{|l|}{} & $\begin{array}{l}\text { Plane } \\
\text { tobacco }\end{array}$ & $\begin{array}{l}\text { Pan } \\
\text { tobacco }\end{array}$ & Gutkha & Betel nut & $\begin{array}{l}\text { Tobacco \& } \\
\text { lime }\end{array}$ & Total \\
\hline $\begin{array}{l}\text { Lesion } \\
\text { present }\end{array}$ & No & 11 & 16 & 77 & 7 & 24 & 135 \\
\cline { 2 - 9 } Total & Yes & 11 & 10 & 41 & 0 & 20 & 82 \\
\hline
\end{tabular}

Table No. 4: Number of participants according to the type of oral lesions.

\begin{tabular}{|l|l|l|}
\hline Type of Lesion & Number of Participants & Percentage \\
\hline OSMF & 37 & 35.57 \\
\hline Leukoplakia & 2 & 1.92 \\
\hline Erythroplakia & 4 & 3.84 \\
\hline Lichen planus & 1 & 0.96 \\
\hline Total & 42 & 100 \\
\hline
\end{tabular}

\section{Discussion:}

In the present study, out of 840 participants, maximum were in the age group of 20-30 years of age $(46.1 \%)$, which is similar to the findings of a study conducted in Bangalore India, where maximum number of the participants were in of age 21-30 years (41.6\%). ${ }^{11}$ In our study males were $52.4 \%$ and females were $47.6 \%$. Similar distribution of sex was seen in the study conducted at Pakistan in which males were $60 \%$ and females were $40 \% .^{12}$ In present study, largest number of participants $44.3 \%$ were unskilled which included people with occupations like labourers, daily wage earners, cleaners, maids, drivers, farmers etc. Similar finding was seen in the study conducted at Bangalore with the same occupation which is $60.2 \%$. Most of these occupations require substantial amount of physical energy and high level of concentration in case of drivers with odd work timings. This can be stressful which in combination of peer pressure can lead to the initiation of deleterious oral habits. ${ }^{11}$ Most of the participants were tobacco chewers $88.7 \%$ followed by smoking habit $6.03 \%$ and both chewing and smoking habit was seen among $5.17 \%$. This was similar to the study done in North Gujarat, regarding the habit of tobacco use, $(21 \%)$ were smokers, $(42 \%)$ tobacco chewers, $(11 \%)$ smokers and chewers. ${ }^{13}$

Among smokeless tobacco chewing $54.3 \%$ used guktha followed by pan and tobacco which was similar to the study done by Saraswathi TR et al, where the participants were more likely to chew pan masala (commercially available processed areca nut product without tobacco) or gutkha (commercially available processed areca nut product with tobacco) $(70 \%) .{ }^{14}$ In our study 232 participants consumed tobacco and out of them 48 consumed more than thrice a day, and lesions were seen in 45 participants and 181 consumed tobacco three or less than three times per day and among them oral lesions were seen in 43 participants. A similar study was conducted in Naigaon, Mumbai where the habit of tobacco consumption was seen in 200 participants and who consumed more than 5 times a day among them 82 had oral lesions. Among those who consumed less than five times a day, 24 of them had oral lesions. The frequency of tobacco consumption is an important risk factor for the development of oral lesion. ${ }^{15}$ The prevalence of oral lesions in our study was $12.4 \%$. Among them, OSMF was $4.40 \%$, leukoplakia was $0.23 \%$ and that of lichen planus was $0.11 \%$. Similar study that was done in Chennai to know the prevalence of oral lesions, it was seen that the prevalence of oral lesion was 4.1\%. Among them leukoplakia was $0.59 \%$ and lichen planus was $0.15 \%$ which is similar to our findings. This shows that urban area prevalence is also similar to the rural area. But there was difference seen in the prevalence of OSMF which was $0.55 \%$ in their study and $4.40 \%$ in our study. OSMF was more because maximum numbers of participants were having the habit of chewing tobacco. In our study erythroplakia was seen among 4 participants $(0.47 \%)$ and similarly it was detected in three patients $(0.15 \%)$ in the study conducted among Turkish population. ${ }^{14,16}$

\section{Conclusion:}

The habit of tobacco chewing and smoking showed a statistically significant association to the development of oral lesions. Chewing of gutkha was most common habit among the study participants which was probably associated with OSMF. These lesions were common in younger age group. Close follow up and 
systematic evaluation is required in this population. There is an urgent need for awareness programs involving the community health workers, dentists and allied medical professionals. The public should be made aware of the high risk of oral malignancy in oral lesions induced by tobacco, gutkha and different habits. More community based interventions should be implemented.

\section{Limitation}

It's a pilot study. More detailed study with detailed diagnostic criteria is in process.

\section{Acknowledgement:}

Authors would like to acknowledge Mr. Mallapur statistician, for his guidance in sample size calculation and analyzing the data. Particularly thank Dr. Nazia for helping us in data collection. We are thankful to all the participants for their participation in the study and staff in Department of Public Health, J.N. Medical College for supporting us in conducting the study.

Conflict of interest: self sponsored study. No conflict of interest.

\section{References:}

[1]. Dhami.J, Ghaffar, Ghafur. WHO: A profile of the premalignant and malignant lesions/conditions inChennai. http://dspace.gla.ac.uk/bitstream/1905/497/1/Dhami_Javaid_ghaffar_Ghafur_Elective.pdf

[2]. Uplap P A, Mishra GA, Majumdar P, Gupta SD, Rane PS , Sadalge PK, Avasare AM .at el. Oral cancer screening at workplace in India-one-year follow-up. Indian journal of Community Medicine.2011; Vol : 36, 2:133-138

[3]. Neufled KJ, Peters DH, Rani M, Bonu S, Bronner RK: Regular use of alcohol and tobacco in India and its association with age, gender, and poverty. Drug Alcohol Depend, 77(3):283-91, 2005.

[4]. Ghom AG. Oral Premalignant Lesions and Conditions. "Textbook of ORAL MEDICINE, Jaypee publishers: $1^{\text {st }}$ ed: 2005; pg 155168.

[5]. Tobacco-related Oral Mucosal Lesions and Dental Diseases: www.corecentre.co.in/Database/Docs/DocFiles/Tobacco_04_7.pdf

[6]. Mehrotra R, Thomas S, Nair P, Pandya S, Singh M, Nigam N, et al. Prevalence of oral soft tissue lesions in Vidisha. http://www.biomedicalcentral.com/1756-0500/3/23

[7]. Byakodi R, Shipurkar A, Byakodi S, Marathe K. prevalence of oral soft tissue lesions in Sangli, India. Journal of Community Health .2011; Vol. 36:5; 756-59.

[8]. Reibel J. Prognosis of oral pre-malignant lesions: significance of clinical, histopathological, and molecular biological characteristics. http://cro.sagepub.com/content/14/1/47

[9]. Ravikiran O, Praveen B N, Text book of Oral Medicine and Oral Radiology. $1^{\text {st }}$ Edition, Publisher: Elsevier, a division of Reed Elsevier India Private limited.

[10]. Gupta PC, Bhonsle RB, Murti P R, Daftary D K, Mehta FS, Pindborg JJ. An epidemiologic assessment of cancer risk in oral precancerous lesions in India with special reference to nodular leukoplakia. Cancer, 1989; Vol 63 11: $2247-52$.

[11]. Sujatha D, Hebbar PB, Pai A : Prevalence and Correlation of Oral Lesions among Tobacco Smokers, Tobacco Chewers, Areca Nut and Alcohol Users, Asian Pacific J Cancer Prev, 13, 1633-1637.

[12]. Rana ZA, Khoso NA, Bajaj DR, Arshad O: Risk factor of precancerous lesion of oral mucosa. Ann. Pak. Inst. Med. 2009; 5(4): 220223.

[13]. P Priyanka, P Viren: Oral mucosal lesions among residence of a town in north gujrat, Vol 1 Issue 1 July - Sept 2011

[14]. Talole KS, Bansode SS, Patki MB: Prevalence of Oral Precancerous Lesions in Tobacco of Naigaon, Mumbai, Indian Journal of Community Medicine, Vol. 31, No. 4 (2006-10 - 2006-12)

[15]. Saraswathi TR, Ranganathan K, Shanmugam S, Sowmya R, Narasimhan PD, Gunaseelan R: Prevalence of oral lesions in relation to habits : Cross-sectional study in South India. Department of Oral and Maxillofacial Pathology, Chennai, India, 2006, Vol.: 17, issue $: 3,121-5$

[16]. Delilbasi C, Akman H, Redzep E, Akal UK. Prevalence of Oral Precancerous lesions in a selected Turkish Population. Received: May 23, 2002. Turk J Med Sci 33(2003)39-42. 